\title{
Time-dependency, predictors and impact on outcome of infarct transmurality assessed by magnetic resonance imaging in patients with st-elevation myocardial infarction reperfused by primary percutaneous intervention
}

\author{
Suzanne de Waha*, Steffen Desch, Ingo Eitel, Georg Fuernau, Philipp Lurz, Matthias Grothoff, \\ Matthias Gutberlet, Gerhard Schuler, Holger Thiele
}

From 2011 SCMR/Euro CMR Joint Scientific Sessions

Nice, France. 3-6 February 2011

\section{Introduction}

Previous studies identifying predictors for transmural infarction in patients with ST-elevation myocardial infarction (STEMI) reperfused by primary percutaneous intervention (PCI), especially analyzing the time-dependency of transmural infarction, achieved inconsistent results and are limited due to small and highly-selected study samples. Furthermore it remains unclear whether transmural infarction assessed within the acute phase of STEMI is associated with adverse clinical outcome.

\section{Methods}

STEMI patients reperfused by primary PCI $(\mathrm{n}=322)$ within $720 \mathrm{~min}$ after symptom-onset underwent contrast-enhanced magnetic resonance imaging (MRI) at a median of 3 days after the index event (interquartile range [IQR 2;4]). Patients were subcategorized into tertiles according to time-to-reperfusion: lower tertile ( $<175 \mathrm{~min}$ ), middle tertile (175-320 $\mathrm{min}$ ) and upper tertile (>320 min). Infarct transmurality was assessed by a score with late-enhancement grading as $<25 \%, 25-50 \%$, $51-75 \%$ and $>75 \%$ transmurality analyzing all 17 left ventricular segments. Transmural infarction was assumed if the hyperenhancement extended $75 \%$ of wall thickness in at least one segment. Clinical follow-up was performed after a median of 20 months (IQR 13;29).
The primary endpoint was defined as a composite of death and congestive heart failure.

\section{Results}

Overall, transmural infarction occurred in 50.6\% $(n=157)$ of all patients. The infarct transmurality score progressed significantly with increasing ischemic time (2.7 [IQR 2.1;3.1] for $<175 \mathrm{~min}, 3.0$ [IQR 2.4;3.4] for 175-320 $\mathrm{min}$ and 3.2 [IQR $2.8 ; 3.5$ ] for $>320 \mathrm{~min}$; $\mathrm{p}<0.001)$.

Using multivariable logistic regression analysis including parameters such as post-PCI TIMI-flow, ST-segment resolution and maximum creatine kinase levels, time-toreperfusion was identified as the only independent predictor for transmural infarction (odds ratio $1.02,95 \% \mathrm{CI}$ 1.01-1.03, $\mathrm{p}=0.03$ ).

Furthermore, in Cox regression analysis neither the presence of transmural infarction nor the transmurality score were associated with the occurrence of the primary composite endpoint (presence of transmural infarction: hazard ratio [HR] 1.22, 95\%CI 0.53-2.79, $\mathrm{p}=0.64$ / transmurality score HR $1.07,95 \% \mathrm{CI} 0.73-1.58$, $\mathrm{p}=0.74)$.

\section{Conclusion}

In STEMI patients reperfused by primary PCI time-toreperfusion is the only independent predictor for

University of Leipzig - Heart Center, Leipzig, Germany

(0) 2011 de Waha et al; licensee BioMed Central Ltd. This is an open access article distributed under the terms of the Creative Commons Attribution License (http://creativecommons.org/licenses/by/2.0), which permits unrestricted use, distribution, and reproduction in any medium, provided the original work is properly cited. 
transmural infarction. However, infarct transmurality is not associated with the occurrence of death and congestive heart failure.

Published: 2 February 2011

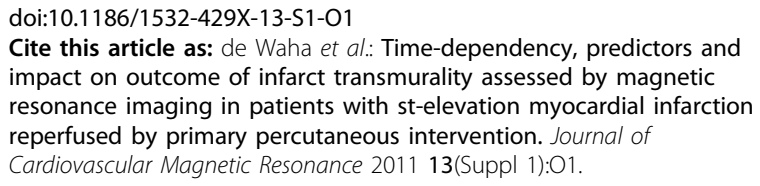

Submit your next manuscript to BioMed Central and take full advantage of:

- Convenient online submission

- Thorough peer review

- No space constraints or color figure charges

- Immediate publication on acceptance

- Inclusion in PubMed, CAS, Scopus and Google Scholar

- Research which is freely available for redistribution 